\title{
Aplicativo Caixa de Música: recurso para aprimoramento das concepções sobre diversidade na Educação Infantil
}

\author{
Priscila Garcia de Sousa e Silva - IFFluminense - priscilasousaesilva@ gmail.com \\ Suzana da Hora Macedo - IFFluminense - shmacedo@iff.edu.br \\ Silvia Cristina Freitas Batista - IFFluminense - silviac@iff.edu.br
}

Resumo: O aplicativo móvel Caixa de Música é um recurso pedagógico colaborativo, gratuito, que integra músicas e atividades autorais sobre diversidade. Seu desenvolvimento requereu uma categorização temática das competências para a Educação Infantil sobre diversidade, seguida de uma pesquisa exploratória por músicas infantis nacionais relacionadas a esse tema. Foram identificadas poucas músicas contemplando temas de diversidade e, assim, foram escritas oito composições, fundamentadas nos documentos regulatórios da Educação Infantil. Este artigo tem por objetivo apresentar o aplicativo e analisar a percepção de professores que o experimentaram em duas turmas da Educação Infantil. A pesquisa teve caráter qualitativo e destacou pontos positivos do aplicativo, dentre os quais o design intuitivo.

Palavras-chave: aplicativo, música, diversidade, Educação Infantil

\section{Music Box app: resource for improving conceptions about diversity in Early Childhood Education}

The Music Box mobile app is a free collaborative educational resource that integrates music and authorial activities about diversity. Its development required a thematic categorization of the competences for Early Childhood Education about diversity, followed by an exploratory research by national children's songs related to this theme. Few songs were identified contemplating diversity themes, and thus, eight compositions were written, based on the regulatory documents of Early Childhood Education. This paper aims to present the app and analyze the perception of teachers who experienced it in two classes of Early Childhood Education. The research had a qualitative character and highlighted positive aspects of the app, among them the intuitive design.

Keywords: app, music, diversity, Early Childhood Education

\section{Introdução}

A música está presente em todos os lugares, integrando o cotidiano das pessoas. Configura-se, desde os primórdios da civilização, como forma de expressão revelandose socialmente parte das culturas. Nessa perspectiva, Mosca $(2009$, p. 37) afirma que a música "[...] faz parte da nossa história enquanto seres coletivos, culturais e transformadores do mundo".

A relação da criança com a música, a partir do brincar, proporciona diversão, conhecimento, novas brincadeiras e interação com o outro. Hortélio (1997, p. 12) afirma que "cada grupo de crianças cria os seus próprios improvisos sonoros". Desta forma, entende-se a produção musical das crianças como parte das culturas infantis.

O Referencial Curricular Nacional para Educação Infantil - RCNEI (Brasil, 1998) defende a música como uma área do conhecimento que pode atender a um propósito interdisciplinar. Nessa perspectiva, o presente trabalho tem por foco o 
aprimoramento da concepção de diversidade, na Educação Infantil, por meio de brincadeiras musicais e do fazer musical, com apoio de tecnologias digitais. A articulação das práticas musicais na Educação Infantil com a tecnologia digital dialoga com o que Lipovetsky e Serroy (2011, p. 8) denominam "grandezas e valores da cultural digital infantil”. Segundo os autores, essas grandezas são: liberdade, participação, colaboração, entretenimento e inovação.

Nesse contexto, foi desenvolvido o aplicativo Caixa de Música ${ }^{1}$, um recurso Web para dispositivos móveis, gratuito. Espera-se contribuir para a construção de um diálogo entre a linguagem musical e as aprendizagens, possibilitando, por meio de interações sociais, o aprimoramento de concepções sobre diversidade, de forma criativa, lúdica e contextualizada. Trata-se de um recurso para o professor utilizar com seus alunos. Tendo em vista a simplificação de escrita do texto, adotar-se-á a usual abreviatura app (do inglês mobile application) para a palavra aplicativo.

A motivação para o desenvolvimento do app decorreu da experiência de sala de aula e da vivência do espaço escolar, compartilhada com professores não músicos, da primeira autora deste artigo, pedagoga, musicista e especialista em educação musical. A consciência da multiplicidade social e psicopedagógica que os desdobramentos do ensino da linguagem musical compreendem e produzem trouxe à tona a expectativa e a responsabilidade de ampliar o papel da música.

A proposta do app requereu, inicialmente, uma categorização temática das competências para a Educação Infantil sobre diversidade, a partir das competências gerais para a educação apresentadas na Base Nacional Comum Curricular - BNCC (Brasil, 2017). A seguir, foi promovida uma pesquisa exploratória por músicas infantis nacionais relacionadas ao tema diversidade, em repositórios de áudio online. Foram identificadas poucas músicas infantis que tratassem do tema e, assim, foram escritas oito composições, fundamentadas nos documentos regulatórios da Educação Infantil.

Buscou-se articular as letras das músicas produzidas com as competências selecionadas para a pesquisa e, assim, estas foram divididas em quatro temas: diversidade nas emoções, diversidade nos sentidos, diversidade cultural e diversidade de personalidade. O app disponibiliza, entre outros recursos, o áudio dessas músicas e um $e$-book com atividades e brincadeiras autorais associadas a essas composições.

O presente artigo tem por objetivo apresentar o app e analisar a percepção de professores que o experimentaram em duas turmas da Educação Infantil de uma Escola Municipal de Macaé, RJ, totalizando 46 crianças. A pesquisa teve caráter qualitativo e os dados referentes à percepção dos participantes sobre a experiência com o app, discutidos neste artigo, foram coletados por meio de entrevista não estruturada e observação participante.

Tendo em vista o exposto, este artigo encontra-se estruturado em cinco seções, além desta introdução. Na seção 2, discutem-se aspectos relacionados à diversidade e à música na Educação Infantil. Na seção 3, são apresentados trabalhos correlatos ao presente estudo. Nas seções 4 e 5, respectivamente, descrevem-se os procedimentos metodológicos adotados e analisam-se os resultados obtidos. Por fim, a seção 6 apresenta algumas considerações sobre o trabalho realizado.

\section{Diversidade e música na Educação Infantil}

A definição de diversidade, apesar de apresentar uma consciência clara de variedade humana, física, social e ambiental, presente na sociedade, contempla complexos significados. Hall (2003) pressupõe, no âmbito das ciências sociais, como a heterogeneidade de culturas, em contraponto à homogeneidade cultural que segue

\footnotetext{
${ }^{1}$ Disponível em: <https://app.vc/nossa_diversidade>.
} 
organizada em torno de valores universais, seculares e individuais.

$\mathrm{Na}$ educação, as discussões a respeito da diversidade têm crescido historicamente. Exemplifica-se esse crescimento com a incorporação da Pluralidade Cultural, nos Parâmetros Curriculares Nacionais - PCN (Brasil, 1997), como tema transversal. É importante ressaltar que o Plano Nacional de Educação - PNE (Brasil, 2001) apresentou capítulos para ressaltar a educação especial e a educação indígena. Moehlecke (2009) atribui esse crescimento, no debate educacional brasileiro, à normatização destas leis do contexto educacional, que evoluiu para normatização da obrigatoriedade no ensino da cultura afro-brasileira e africana e da cultura indígena nos currículos escolares.

Para Candau (2016), existe uma impotência no contexto educacional. A comunidade educativa parece não saber como responder positivamente às questões das diferenças culturais. Coerente a este pensamento, Perrenoud (2001, p. 70) afirma que o professor busca familiarizar o aluno com as questões de diversidade, mas isto não se apresenta como "[...] sinônimo de tolerância e de aceitação das diferenças". Dentre as diversas concepções de educação intercultural que permeiam a literatura, propõe-se refletir e discutir a perspectiva da interculturalidade crítica, preconizada por Walsh (2012) e difundida nos círculos culturais de Paulo Freire, na emancipação dos sujeitos.

A visão base da interculturalidade crítica promove o direcionamento a um conceito de educação intercultural, que é admitido, no presente estudo, como referência para fundamentar e discutir as práticas educacionais na Educação Infantil. Nesse contexto, concorda-se com Candau (2014, p. 1) que "A Educação Intercultural parte da afirmação da diferença como riqueza".

Pelo exposto, defende-se como fundamental o desenvolvimento de concepções sobre diversidade, na Educação Infantil, a partir de uma prática docente na interculturalidade, na intenção de responder aos desafios da sociedade e da educação. Nessa perspectiva, considera-se que a linguagem musical pode trazer contribuições importantes para a construção dos significados.

A música está presente para a criança desde seu momento intrauterino. A relação com o ambiente sonoro se mostra de forma evolutiva e se desenvolve, segundo as pesquisas de Northern e Downs (1989), a partir da vigésima semana de gestação, momento em que o feto esboça reações aos estímulos sonoros. Porém, apesar dessa conexão da música à vida desde antes do nascimento, faz-se necessário percebê-la como linguagem artística e como tal deve estar presente na educação. Segundo Gohn e Stavracas (2010), o ensino da arte é papel do educador e a introdução ao mundo musical deve ser efetivada pelo professor, à medida que promove exploração do universo sonoro por meio de planejamento que reflita essa intencionalidade.

Outrossim, Gohn e Stavracas (2010) consideram que a música na escola, instituída por meio do planejamento de atividades, deve ser entendida como musicalização e pode auxiliar o aluno a desenvolver diversas habilidades, como: i) controle rítmico-motor; ii) uso da voz falada e cantada; iii) criatividade; iv) percepções auditiva, visual e tátil; v) concentração, atenção, raciocínio, memória, associação, dissociação, codificação e a decodificação.

A perspectiva da música na educação apresenta-se como possibilidade para valorizar a infância e suas linguagens. Segundo Gainza (2015) e Swanwick (2003), as práticas musicais escolares são responsáveis pela ampliação do significado social, produção de sentidos e construção de novos significados. Assim, a música pode contribuir para o aprimoramento da concepção de diversidade na Educação Infantil.

Nesse cenário, as tecnologias digitais podem contribuir como recurso pedagógico para ampliar possibilidades de diálogo com a música, por meio de 
atividades. Tais tecnologias, segundo Menezes e Couto (2012), permitem promover registros autorais de improvisos, invenções, expressões, histórias, dramatizações e, também, articular mixagens sonoras que podem resultar em misturas e experimentações importantes para validar a autoria na infância e observar suas percepções.

Segundo Farias (2015), houve um crescimento de tecnologias digitais para entretenimento musical, em relação aos aplicativos classificados em outras categorias de entretenimento. Entre eles, os jogos musicais, simuladores de instrumentos, para mixagem, criação, reprodução, audição e exercício musical. Couto (2013) afirma que estes aplicativos, utilizados em atividades no contex to educacional, podem aproximar as ações educativas à cultura digital da infância, dando novo significado ao patrimônio cultural musical infantil. Da mesma forma, Gohn (2016) afirma que os aplicativos para dispositivos móveis ressignificam os espaços, transformando qualquer local em estúdio de gravação, mixagem, ambiente para exploração de instrumentos, galeria de repertório musical e museu.

\section{Trabalhos correlatos}

Nesta seção, discutem-se, brevemente, três estudos recentes, nos quais são analisadas possibilidades educacionais apresentando vieses da educação infantil na diversidade, educação musical e tecnologia digital.

O trabalho de Mansikka et al. (2018) analisou aspectos críticos da diversidade cultural na educação musical e procurou examinar as práticas estabelecidas e formas culturais na Finlândia. Tratou-se de uma pesquisa qualitativa, do tipo estudo de caso, para investigar como os professores abordavam a diversidade em sala de aula, considerando o contexto intercultural da Finlândia e seus processos migratórios. Almejou-se responder se a educação musical reproduzia um repertório uniforme ou diversificado e se as aulas buscavam desenvolver uma relação mais ampla com a música, com base em uma abordagem crítica, inclusiva e multicultural.

Os dados foram coletados por meio de entrevistas em grupos focais com professores envolvidos com práticas musicais de quatro escolas finlandesas de língua sueca. Para a análise dos dados coletados nas entrevistas foi utilizada a análise qualitativa de conteúdo. Como resultado, os autores verificaram que a criticidade para promover a educação musical em sala aumentou, mas, apesar disso, relatou-se que a abordagem inclusiva prevalecia, em detrimento de ações e reflexões críticas sobre a educação musical multicultural. A pesquisa identificou relutância dos docentes em desenvolver uma dimensão mais transcultural na educação musical. Os autores relataram ainda, a necessidade do docente se conscientizar em utilizar uma lente crítica na educação musical multicultural para minimizar mecanismos de exclusão.

A pesquisa realizada por Hajisoteriou et al. (2017) buscou examinar as percepções infantis e suas conceituações sobre a diversidade cultural. O estudo foi realizado em cinco escolas primárias, abrangendo 40 alunos, sendo 50\% imigrantes. Cada escola pertencia a um distrito diferente de Chipre. Como procedimento metodológico, foi utilizada a abordagem qualitativa do tipo etnográfica, com coleta de dados por meio de entrevista um a um, gravada. Por meio de um guia de entrevistas, os autores buscaram perceber como se davam as conceituações das crianças sobre diversidade cultural, educação intercultural e as relações entre pares. Além das entrevistas, foram utilizados outros recursos, como desenhos, fotos e fotografias pertinentes a questões como discriminação, estereótipos, comportamento e diversidade.

$\mathrm{Na}$ análise dos dados, foi utilizada a metodologia Análise de Conteúdo e os resultados evidenciaram a dificuldade das crianças em estabelecer conceitos concretos quanto à diversidade cultural. Deste modo, esta pesquisa sinalizou a necessidade de 
intensificar a prática docente para "cristalizar" as concepções infantis sobre diversidade.

Fecchio et al. (2018) descrevem a construção de um aplicativo musical de realidade aumentada, para sistema Android, como recurso educacional para as aulas de musicalização infantil. O objetivo foi contribuir para a percepção musical, por meio de atividades de vivência musical e diferenciação de instrumentos musicais. O públicoalvo deste aplicativo são crianças alfabetizadas, de 7 a 14 anos. O trabalho foi aplicado com um grupo de 12 crianças, previamente niveladas quanto ao conhecimento musical, por meio de questionário de pré-teste. Após a aplicação, com tempo médio de 20 minutos, os participantes responderam ao questionário pós-teste, com objetivo de avaliar os conhecimentos adquiridos, e também a um questionário de avaliação de satisfação. Os resultados apontaram que, para todos os participantes, ocorreu ampliação do conhecimento sobre novos instrumentos. Além disso, a maioria das crianças soube diferenciar instrumentos musicais após a aplicação. Quanto à satisfação, foi unânime que o aplicativo poderia ser utilizado sem ajuda, que as cores eram favoráveis e que o app era de fácil utilização. Identificou-se, no grupo de aplicação, que foi o primeiro contato das crianças com esse tipo de recurso educacional para musicalização.

Os trabalhos de Mansikka et al. (2018) e Hajisoteriou et al. (2017) sinalizaram uma necessidade de pesquisas que apontem possibilidades e aprofundamentos da abordagem intercultural para uma transformação da prática docente. Evidenciou-se no trabalho de Fecchio et al. (2018) que a articulação da tecnologia com o contexto musical trouxe contribuições para percepção musical.

Diferentemente do aplicativo proposto por Fecchio et al. (2018), o app Caixa de Música não usa realidade aumentada, mas, por outro lado, este é um recurso integrador e colaborativo. Além disso, apresenta embasamento contextual específico para atividades e materiais autorais com a finalidade de ampliar a musicalidade e contribuir para o aprimoramento das concepções infantis sobre diversidade.

\section{Material e Métodos}

Inicialmente, para categorização dos temas sobre diversidade foi realizada uma pesquisa documental, nos documentos regulatórios para Educação Infantil. Assim, foram identificadas as prerrogativas estabelecidas em relação à diversidade para apoiar as atividades e composições musicais. A seguir, foi promovida uma pesquisa exploratória sobre músicas relacionadas ao tema, realizada em dois períodos intercalados, outubro de 2017 e abril de 2018, nos principais serviços de streaming de música, no Brasil. A condição determinante para a busca, nestes repositórios, foi a possibilidade de acesso gratuito, ou, pelo menos, a existência de versão gratuita, sendo eles: Youtube; Spotify; SoundCloud e Deezer. Foram utilizados para a busca os seguintes descritores: diversidade, diferença, diferente, iguais, cultura, emoções. Dos dois períodos da pesquisa exploratória, resultaram 56 músicas, que foram analisadas, classificadas e relacionadas quanto ao tema geral da letra e público-alvo.

Por meio dessa pesquisa, observou-se que alguns temas eram inexistentes e outros apresentavam baixo número, quando comparado às especificidades propostas para elucidar a diversidade na Educação Infantil. Diante dessa realidade, realizou-se a delimitação temática para composição de oito músicas infantis relacionadas à diversidade. Buscou-se articular as letras das músicas com as competências selecionadas para a pesquisa, as quais foram extraídas dos documentos regulatórios. As composições foram divididas em quatro temas: diversidade nas emoções, diversidade nos sentidos, diversidade cultural e diversidade de personalidade.

Buscando integrar as músicas produzidas e outros recursos associados, elaborados na pesquisa, foi desenvolvido o app Caixa de Música (Figura 1). Para tanto, 
foram utilizados programas gratuitos ou versão gratuita de serviços online, a saber: plataforma para fabricação de aplicativo - Fábrica de Aplicativos; design gráfico Canva; imagens -Pixabay; ilustração - Bitmoji e formulário - Cognito Forms.

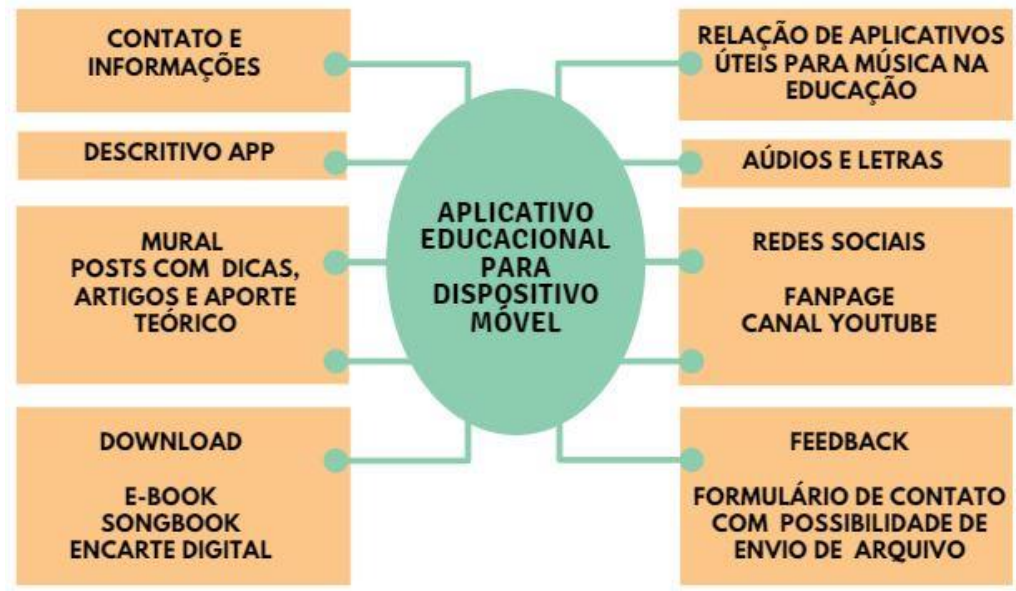

Figura 1 - Esquema do app Caixa de Música

Fonte: Elaboração própria.

A experimentação do app, analisada neste trabalho, foi realizada com duas turmas de Educação Infantil, de uma Escola Municipal de Macaé, totalizando 46 crianças e três professoras, sendo duas da turma A e uma da turma B. A primeira autora deste trabalho observou a experiência, promovida em dois encontros, cada um com 50 min, ministrados em duas quintas-feiras consecutivas, em outubro de 2018. O conteúdo abordado foi diversidade nas emoções e diversidade de personalidades. A faixa etária dos alunos participantes da experimentação era de 4 a 6 anos.

A pesquisa promovida teve caráter qualitativo e os dados referentes à percepção das professoras sobre a experiência com o app, discutidos neste artigo, foram coletados por meio de entrevista não estruturada e observação participante sobre as atividades propostas, descritas no Quadro 1. Ressalta-se que a coleta e a divulgação dos resultados da pesquisa foram autorizadas pelos professores, em termo específico para tal fim.

Quadro 1 - Sucinta descrição de atividades

\begin{tabular}{|c|c|c|c|}
\hline \multirow{3}{*}{$\begin{array}{l}\mathbf{1}^{\circ} \text { Período } \\
\text { de } \\
\text { Atividades }\end{array}$} & \multirow{3}{*}{$\begin{array}{l}1 \text { - Explorar a } \\
\text { diversidade das } \\
\text { emoções; } \\
2 \text { - Relacionar emoções } \\
\text { com as expressões. } \\
\text { Música: Toda Emoção } \\
\text { tem Nome }\end{array}$} & Audição & $\begin{array}{l}\text { Momento de ouvir e se expressar } \\
\text { livremente com a música. }\end{array}$ \\
\hline & & Expressão & $\begin{array}{l}\text { Roda de conversa; } \\
\text { Reconhecer a emoção do emoji; }\end{array}$ \\
\hline & & Improvisação & $\begin{array}{l}\text { Narrativas Digitais de Histórias; } \\
\text { Evidenciar as emoções dos } \\
\text { personagens; } \\
\text { Registro das percepções. }\end{array}$ \\
\hline \multirow{3}{*}{$\begin{array}{c}2^{\circ} \text { Período } \\
\text { de } \\
\text { Atividades }\end{array}$} & \multirow{3}{*}{$\begin{array}{l}\text { 1- Explorar a } \\
\text { diversidade pessoal } \\
\text { Música: } \\
\text { Todo Cabelo é Bom }\end{array}$} & Audição & $\begin{array}{l}\text { Momento de ouvir e se expressar livre- } \\
\text { mente com a música. }\end{array}$ \\
\hline & & Expressão & $\begin{array}{l}\text { Ritmo, pulsação; } \\
\text { Corpo e movimento. }\end{array}$ \\
\hline & & Improvisação & Registro das percepções. \\
\hline
\end{tabular}

Fonte: Elaboração própria. 


\section{Resultados e Discussão}

\subsection{O aplicativo Caixa de Música}

Integram o app oito composições autorais, songbook e e-book de atividades. As composições foram registradas como coletânea intitulada Nossa Diversidade, na seguinte ordem: Todo mundo faz nhém nhém nhém, Toda emoção tem nome, Nossos sentidos, É bom sentir, Super sentidos, Cada esporte é do seu jeito, Todo cabelo é bom, Jeito de entender a vida. Os materiais estão representados no app conforme a Figura 2.
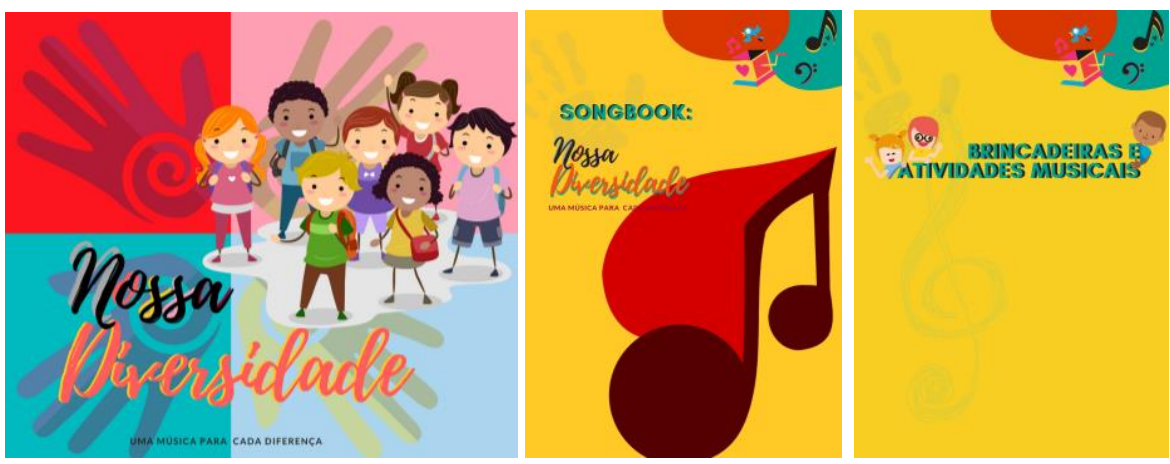

Figura 2 - Materiais autorais do app

Fonte: Elaboração própria.

O aplicativo está composto por ícones divididos por áreas, conforme descritivo:

1. Área com conteúdo descritivo do aplicativo: vídeo tutorial com descrição do conteúdo do aplicativo;

2. Área de áudio: músicas autorais com voz guia e letras;

3. Área de download é composta de materiais para download e visualização: i) $e$-book com atividades e brincadeiras autorais, baseadas nas músicas sobre diversidade, mediadas por tecnologias digitais; ii) encarte digital com as letras para consulta; iii) songbook com partitura e cifra facilitada para execução por músicos iniciantes ou amadores;

4. Área para colaboração de materiais;

5. Área para contato: feedback, contato e informações;

6. Área para interação docente: i) canal do Youtube personalizado; ii) fanpage personalizada; iii) mural, artigos e disponibilização de aporte teórico; iv) relação de app com suas possibilidades e potencialidades para uso em sala de aula por meio de atividades musicais;

Os ícones foram representados conforme Figura 3.

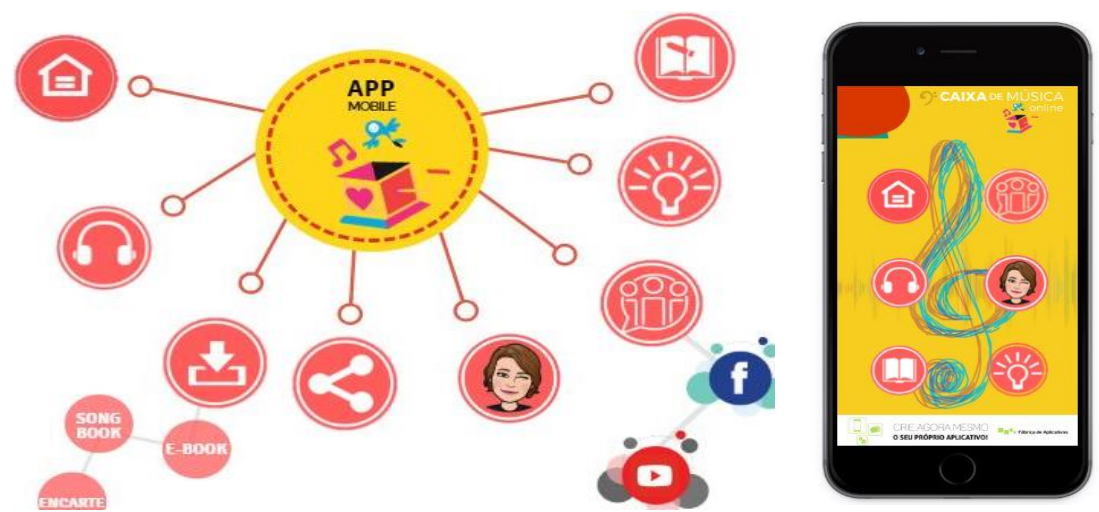

Figura 3 - Design app Caixa de Música

Fonte: Elaboração própria. 


\subsection{Percepção dos professores}

$\mathrm{Na}$ experimentação promovida, a facilidade para acesso aos materiais que integram o app foi bastante evidenciada. Além disso, os professores destacaram que o app não demanda espaço de memória para sua utilização, apresenta um layout agradável e sugestão de recursos que ressignificam a prática pedagógica. Durante as ações de sala de aula, os professores manifestaram contentamento na utilização, consulta às atividades e seleção de recursos.

O uso do app contribuiu positivamente para a experiência promovida, indo muito além de permitir ao professor utilizar um recurso digital. A utilização trouxe melhoria na rotina das turmas, pois não foi necessário agendar uma sala específica com os recursos físicos para audição musical, evitando, assim, locomoção entre os espaços, otimizando o tempo em sala de aula.

$\mathrm{Na}$ entrevista, entre os pontos positivos, foi destacado o acesso rápido aos materiais e músicas, sem que se tenha que aguardar uma busca, como é o caso dos streamings de áudio. Desta forma, houve maior rapidez e prontidão na sala de aula para audição musical do que se costumava ter. Além disso, os professores afirmaram que o app possui um design intuitivo, com ícones de fácil reconhecimento das funcionalidades disponíveis.

Em contrapartida, foi apontado que o uso do app implica necessariamente acoplagem de caixa de som para ampliação sonora, material que não havia disponível em sala de aula. Quando utilizado sem a caixa de som, foi alegado por um dos professores que houve dispersão dos alunos pelo baixo volume. No entanto, o outro professor preferiu usar sem ampliação sonora, e justificou que há maior esforço dos alunos para audição musical, o que apresentou maior concentração para o momento proposto. Neste sentido, recomenda-se um tempo maior de experimentação com alunos em diferentes faixas etárias para avaliação sobre as possibilidades de concentração na audição musical com baixo volume.

As atividades propostas foram avaliadas como eficientes na integração da temática e as músicas que integram o app foram apontadas pelos professores como sendo um material de qualidade superior ao disponível nos streamings de áudio online. Foi percebido pelos professores que há uma grande necessidade de abordagem quanto à diversidade. Durante as atividades propostas, foi identificado que alguns alunos não percebiam as diferenças físicas uns dos outros, o que trouxe grande desconforto para os professores que afirmaram que não percebiam a temática diversidade tão distante dos alunos.

\section{Considerações Finais}

A revisão bibliográfica deste trabalho ressaltou uma incipiente abordagem docente sobre a temática diversidade. Verificou-se, apesar de não ser o objetivo principal, que o docente, na Educação Infantil, tende a realizar uma abordagem superficial que pode vir a ser objeto de aprofundamento de estudo.

A avaliação do app quanto ao design intuitivo mostrou-se determinante característica para validar o uso no ambiente educacional. Os professores demonstraram muita satisfação e entusiasmo, dadas as facilidades apresentadas pelo app. Para estes professores, foi a primeira utilização de um aplicativo por meio do próprio dispositivo móvel em sala de aula, na Educação Infantil.

Além disso, destacou-se, de forma unânime, que o uso do dispositivo móvel contribuiu para a otimização do tempo, no que tange à diminuição de deslocamentos. A descrição de outros aplicativos com sugestões de uso em sala de aula, disponível no app, foi objeto de consulta e planejamento dos professores para futuras ações. Foi 
possível observar que a experimentação do app impulsionou uma reflexão docente sobre as possibilidades do dispositivo móvel em sala de aula e sobre a percepção dos alunos acerca da diversidade.

Como perspectiva de continuidade de aprimoramento do app, pretende-se realizar outras experimentações, ampliando o número de professores participantes.

\section{REFERÊNCIAS}

BRASIL. Parâmetros Curriculares Nacionais (PCN): Anos Iniciais do Ensino Fundamental. Secretaria de Educação Fundamental. Brasília: MEC, 1997. Disponível em: <http://portal.mec.gov.br/seb/arquivos/pdf/pluralidade.pdf〉. Acesso em: 18 fev. 2018.

. Plano Nacional de Educação (PNE). Ministério da Educação. Brasília, DF: INEP, 2001. Disponível em: < http://www.planalto.gov.br/CCIVIL_03/_Ato20112014/2014/Lei/ L13005.htm>. Acesso em: 18 fev. 2018.

. Base Nacional Comum Curricular (BNCC). Secretaria de Educação Básica. Brasília, MEC/CONSED/UNDIME, 2017. Disponível em:

$<$ http://basenacionalcomum.mec.gov.br/wp content/uploads/2018/04/RESOLUCAOCNE_CP222DEDEZEMBRODE2017.pdf >. Acesso em: 02 jun. 2018.

. Referencial Curricular Nacional para a Educação Infantil (RCNEI). Secretaria de Educação Fundamental. Brasília: MEC/SEF, 1998. v. 3. Disponível em: <http://portal.mec.gov.br/seb/arquivos/pdf/rcnei_vol1.pdf>. Acesso em: 18 out. 2017.

CANDAU, V. M. F. Cotidiano escolar e práticas interculturais. Cadernos de Pesquisa, v. 46, n. 161, p. 802-820, set. 2016. Disponível em:

<http://www.scielo.br/pdf/cp/v46n161/1980-5314-cp-46-161-00802.pdf>. Acesso em: 12 abr. 2018.

Ser professor/a hoje: novos confrontos entre saberes, culturas e práticas. Educação (Porto Alegre, impresso), v. 37, n. 1, p. 33-41, jan./abr. 2014. Disponível em: <http://revistas eletronicas.pucrs.br/ojs/index.php/faced/article/view/15003/10923>. Acesso em: 13 jul. 2018.

COUTO, E. S. A infância e o brincar na cultura digital. Perspectiva, Florianópolis, v. 31, n. 3, 897-916, set./dez. 2013. Disponível em:

<https://periodicos.ufsc.br/index.php/perspectiva/article/view/2175-

795X.2013v31n3p897>. Acesso em: 18 ago. 2018.

FARIAS, F. M. Suporte para a criatividade musical cotidiana: mixDroid Segunda Geração. Dissertação de Mestrado, Universidade Federal do Rio Grande de Sul, Porto Alegre, 2015. Disponível em:

<https://www.lume.ufrgs.br/bitstream/handle/10183/134340/

000988398.pdf?sequence=1\&isAllowed=y> . Acesso em: 20 ago. 2018.

FECCHIO, D. Y. et al. Instrumenteca RA: Um Objeto de Aprendizagem para Auxiliar a Percepção Musical através da Diferenciação dos Sons de Instrumentos Musicais.

RENOTE, v. 16, n. 1, ago. 2018. Disponível em: <https://seer.ufrgs.br/renote/article/view/85988/49357>. Acesso em: 29 out.2018.

GAINZA, V. H. de. A improvisação musical como técnica pedagógica. In: SILVA. H.

L. da; ZILLE, J. A.B. (Org) Música e Educação: Séries Diálogos com o som.

Barbacena: Ed. EDUEMG, 2015. v. 2. Disponível em:

$<$ https://musicaeinclusao.files.wordpress.com/2015/09/livro-na-integra.pdf >. Acesso em 25 out. 2018. 
GOHN, D. Tecnologia na educação musical: possibilidades e perigos. In: V I Encontro de Pesquisa e Extensão do Grupo Música e Educação Mus, 2016, Florianópolis. Anais... 2016. v. 1, p. 26-33. Disponível em:

$<$ https://grupodepesquisamuse.files.wordpress.com/2015/04/anais-do-vi-encontro-domuse-26-07-v-final31.pdf> Acesso em: 12 ago. 2018.

GOHN, M. da G.; STAVRACAS, I. O papel da música na Educação Infantil. EccoS, São Paulo, v. 12, n. 2, p. 85-101, jul./dez. 2010. Disponível em: < http://www.redalyc .org/pdf/715/71518580013.pdf>. Acesso em: 09 out.2018.

HAJISOTERIOU, C.; KAROUSIOU C.; ANGELIDES, P. Mapping cultural diversity through children's voices: From confusion to clear. Understandings. University of Nicosia, Cyprus. British Educational Research Journal, v. 43, n. 2, 2017, p. 330-349 DOI: 10.1002/berj.3266. Disponível em: <https://onlinelibrary.wiley.com/doi/epdf/10.1002/berj.3266>. Acesso em: 08 jun. 2018.

HALL, S. Diáspora: identidades e mediações culturais. Belo Horizonte, UFMG, 2003 p. $51-100$.

HORTÉLIO, L. História de Uma Manhã. Massao Ohno: São Paulo, 1997.

LIPOVETSKY, G.; SERROY, J. A cultura-mundo: resposta à uma sociedade desorientada. Tradução de Maria Lucia Machado. São Paulo: Companhia das Letras, 2011.

MENEZES, J. A.; COUTO, E. S. Clicar e brincar: o lúdico na cibercultura infantil. In: ARAPIRACA, M.; BELTRÃO, L. F.; SUZART, C. Estudos e passagens do Proinfantil na Bahia. Salvador: EDUFBA, 2012. p. 145-152.

MANSIKKA, J. E.; WESTVALL, M.; HEIMONEN, M. Critical aspects of cultural diversity in music education: examining the established practices and cultural forms in minority language schools in Finland, Intercultural Education, 29:1, 59-76, 2018. Disponível em: <https://doi.org/10.1080/1467 5986.2017.1404784>. Acesso em: 07 jun. 2018.

MOEHLECKE, S. As políticas de diversidade na educação no governo Lula. Cadernos de Pesquisa [online]. 2009, v.39, n.137, p. 461-487. Disponível em: <http://www.scielo.br/scielo.php?script=sci_arttext\&pid=S0100$15742009000200008 \& \operatorname{lng}=$ en\&nrm=iso>. Acesso em: 05 jun. 2018.

MOSCA, M. de O. Como se fora brincadeira de roda: a ciranda da ludopoiese para uma educação musical humanescente. Natal-RN, 2009.180 f. Dissertação (Mestrado em Educação) - Universidade Federal do Rio Grande do Norte. Centro de Ciências Sociais Aplicadas. Programa de Pós-Graduação em Educação. Disponível em: <https://repositorio.ufrn.br/ jspui/handle/123456789/14388>. Acesso em: 07 out. 2018.

NORTHERN, J. L; DOWNS, M. P. Audição em crianças. 3. ed. São Paulo: Manole, 1989.

PERRENOUD, P. A pedagogia na escola das diferenças: fragmentos de uma sociologia do fracasso. Porto Alegre: Artmed, 2001.

SWANWICK, K. Ensinando Musica Musicalmente. São Paulo: Modena, 2003.

WALSH, C. Interculturalidad y (de)colonialidad: Perspectivas críticas y políticas. Visão Global, Joaçaba, v. 15, n. 1-2, p. 61-74, jan./dez. 2012. Disponível em: <https://editora.unoesc.edu.br/index.php/visaoglobal/article/view/3412/1511>. Acesso em: 13 ago. 2018. 